\title{
Ways of Explaining Workplace Bullying: A Review of Enabling, Motivating, and Precipitating Structures and Processes in the Work Environment
}

Published in Human Relations, 56, 10, 1213-1232

Denise Salin

Swedish School of Economics and Business Administration

Department of Management and Organisation

P.O.Box 479, FIN-00101 Helsinki, Finland

e-mail: denise.salin@hanken.fi, telephone +358-40-3521 563 


\section{WAYS OF EXPLAINING WORKPLACE BULLYING: A REVIEW OF \\ ENABLING, MOTIVATING, AND PRECIPITATING STRUCTURES AND PROCESSES IN THE WORK ENVIRONMENT}

This paper summarizes literature explaining workplace bullying and focuses on organisational antecedents of bullying. In order to better understand the logic behind bullying, a model discussing different types of explanations is put forward. Thus, explanations for and factors associated with bullying are classified into three groups, i.e. enabling structures or necessary antecedents (e.g. perceived power imbalances, low perceived costs, and dissatisfaction and frustration), motivating structures or incentives (e.g. internal competition, reward systems, and expected benefits), and precipitating processes or triggering circumstances (e.g. downsizing and restructuring, organisational changes, changes in the composition of the workgroup). The paper concludes that bullying is often an interaction between structures and processes from all three groupings.

Key words: aggression, bullying, harassment, review, work environment 


\section{EXPLAINING WORKPLACE BULLYING: A REVIEW OF ENABLING, MOTIVATING, AND PRECIPITATING STRUCTURES AND PROCESSES IN THE WORK ENVIRONMENT}

During the past decade bullying has received growing attention in organization research. Researchers have reported alarming findings about the negative consequences associated with bullying, both for the individuals and the organizations concerned. As for the effects on the organization, bullying has been shown to be associated with higher turnover and intent to leave the organization, higher absenteeism, and decreased commitment and productivity (Hoel, Einarsen \& Cooper, 2003; Keashly \& Jagatic, 2003). In addition, for the victim bullying has been reported to result in both lower levels of job satisfaction, psychosomatic symptoms and physical illness, and possible expulsion from the labour market (Hoel \& Cooper, 2000; Keashly \& Jagatic, 2003; Leymann, 1996; Vartia, 2001). Thus, bullying is most costly both for organizations and the society as a whole (cf. Leymann, 1992a). What is more, whereas substantive task conflict has been shown to increase performance under certain circumstances, affective relationship conflict, which bullying usually is, does not have such positive effects (Jehn, 1995).

The severe negative outcomes have made workplace bullying and other forms of hostile interpersonal behaviours issues of great public interest and have led a growing number of researchers to study them. Researchers have made several attempts to more precisely define the concept and nature of workplace bullying (e.g. Leymann, 1996; Liefooghe \& Mackenzie Davey, 2001), to describe the prevalence and forms of bullying (e.g. Einarsen \& Skogstad, 1996; Hoel \& Cooper, 2000; Leymann, 1992a; O'Moore, 2000), and to identify personality traits and organizational factors associated with bullying and 
aggression (e.g. Aquino, Grover, Bradfield \& Allen, 1999; Coyne, Seigne \& Randall, 2000; Einarsen, Raknes \& Matthiesen, 1994; Neuman \& Baron, 1998; Vartia, 1996; Zapf, Knorz \& Kulla, 1996). However, although a number of empirical studies have been conducted to examine the correlation between bullying and certain work environment factors, few studies have discussed in more detail the organizational dynamics behind bullying, i.e. how and why these organizational conditions and processes may contribute to it.

The aim of this paper is thus to summarize literature on work environment factors explaining workplace bullying and to build a model discussing in more depth the role of the different factors that contribute to the process. To gain a richer understanding of bullying and hostile interpersonal behaviours insights from European research on bullying and mobbing are combined with North American research on anti-social, incivil or aggressive interpersonal behaviour in the workplace.

This paper begins with an attempt to define and delineate workplace bullying. Thereafter, explanations for bullying are sought and a model is put forward, classifying structures and processes associated with bullying into three groupings, enabling structures or necessary antecedents; motivating structures or incentives; and precipitating processes or triggering circumstances.

\section{WHAT IS WORKPLACE BULLYING?}

In this article bullying is defined as repeated and persistent negative acts towards one or more individual(s), which involve a perceived power imbalance and create a hostile work environment (cf. Einarsen, 1996; Hoel \& Cooper, 2000; Zapf et al., 1996). Bullying is thus a form of interpersonal aggression or hostile, anti-social behaviour in the workplace. Several terms have been used to describe various aspects of 
interpersonal aggression (see Keashly \& Jagatic, 2003). Here a few of these related concepts are identified. The characteristics of bullying and contrasts to related concepts are discussed in more detail later.

As for the term bullying it can be noted that is has predominantly been used by researchers in the UK and Ireland (e.g. Hoel \& Cooper, 2000; O’Moore, 2000; Rayner, 1997), Australia (e.g. McCarthy, 1996; Sheehan, 1996) and Northern Europe (e.g. Einarsen, 1996; Salin, 2001; Vartia, 1996), whereas German researchers (e.g. Zapf et al., 1996) have used the term 'mobbing' for the same phenomenon. In North America related and partly overlapping phenomena have been studied under a plethora of different names. These terms include 'employee abuse' (e.g. Keashly, 1998), 'workplace aggression' (e.g. O'Leary, Griffin \& Glew, 1996; Neuman \& Baron, 1998), 'victimization' (e.g. Aquino et al., 1999), 'interpersonal deviance’ (e.g. Bennett \& Robinson, 2003), 'social undermining' (e.g. Duffy, Ganster \& Pagon, 2002) and 'workplace incivility' (e.g. Andersson \& Pearson, 1999; Cortina, Magley, Williams \& Langhout, 2001). All of these are used to describe forms of interpersonal aggression and hostile workplace behaviours and do to varying extents overlap with the term bullying, although some differences are identified later.

As for the contents of bullying, it may consist of and encompass a number of different negative behaviours such as social isolation or silent treatment, rumours, attacking the victim's private life or attitudes, excessive criticism or monitoring of work, withholding information or depriving responsibility, and verbal aggression (Einarsen, 1996; Keashly, 1998; O'Moore, 2000; Zapf et al., 1996). Compared to some general literature on victimisation and violence, acts of physical violence tend to be rather rare in bullying. However, bullying is interpersonal by nature, thus being a narrower concept than anti-social or deviant workplace behaviour, which may also involve acts directed 
towards the organization (Giacalone \& Greenberg, 1997; Robinson \& Bennett, 1995). What is more, bullying typically takes place between members of the organization, in contrast to other forms of interpersonal violence and aggression, which may involve outsiders.

The major difference between 'normal' conflict and bullying is not necessarily what and how it is done, but rather the frequency and longevity of what is done. Einarsen \& Skogstad (1996) and Vartia (1996) stress that bullying is repeated, persistent and continuous behaviour; typically single negative acts are not considered bullying. In contrast with literature on workplace aggression (Neuman \& Baron, 1998) and social undermining (Duffy et al., 2002), intent is typically not part of the definition, but instead the subjective perception of the victim is stressed (cf. Hoel \& Cooper, 2001). The emphasis has been on the target's own perceptions, since it can be assumed that many of the reported consequences of bullying, such as ill-health, reduced commitment and decreased productivity, are strongly associated with the target's own evaluation of the situation.

Bullying is typically targeted towards one or a few selected victims, rather than being a form of more generalized workplace incivility. What is more, not all acts that can be used as bullying tactics are necessarily perceived as negative per se. For example, isolated occasions of being given tasks below one's level of competence, being given a tight deadline or not being asked to join colleagues for lunch or another social event would most likely been seen as normal and neutral features of work life. However, such acts may become negative, and thus bullying, when they are used in a systematic manner over a longer period of time, resulting in an unpleasant and hostile work environment. Furthermore, bullying shows many similarities with sexual harassment in workplaces, even if the sexual element is missing. The concept of 'hostile work 
environment' has been adopted from existing definitions of sexual harassment (cf. Pryor \& Fitzgerald, 2003), showing that both phenomena are different forms of work harassment, which have severe consequences for the well-being and job satisfaction of the target.

Moreover, bullying has been seen as involving a power imbalance or a 'victimperpetrator' dimension, i.e. the target is subjected to negative behaviour on such a scale that he or she feels inferiority in defending him- or herself in the actual situation (Einarsen \& Skogstad, 1996; Keashly, 1998). Conflicts between parties of perceived equal strength are thus not considered bullying (Einarsen \& Skogstad, 1996; Vartia, 1996). Formal power differences are a possible source of such an imbalance in power, but in contrast to for example 'petty tyranny' (Ashforth, 1994) bullying is not limited to vertical aggression from supervisors towards subordinates. As power imbalances can also be the consequence of other individual, situational or societal characteristics (cf. Cleveland \& Kerst, 1993), the required power differences can also arise among peers. In some cases even subordinates, especially if acting in a group, may muster enough power to bully a supervisor. In addition, it should be noted that power imbalances may also evolve over time and that the bullying process itself may give rise to further increasing power imbalances.

\section{WAYS OF EXPLAINING WORKPLACE BULLYING}

Several attempts to explain the occurrence of workplace bullying have been made. Whereas some researchers have focused on personality traits of perpetrators and victims (e.g. Coyne et al., 2000), others have emphasized the role played by deficiencies in the work environment (e.g. Einarsen, 1996; Leymann, 1992a; Vartia, 1996; Zapf et al., 1996). What is more, group processes, such as scapegoat processes, have been brought 
up by some researchers (e.g. Thylefors, 1987). However, to a growing extent researchers are acknowledging that bullying and other forms of aggression often are the result of an interaction between individual and situational factors (Aquino et al., 1999; Neuman \& Baron, 1998; O'Leary-Kelly et al., 1996; Zapf, 1999). In addition, the individual and the organization may exert mutual influence on each other, both in the sense that an individual may acquire aggressive tendencies in a certain environment and in the sense that the work environment and the work culture may be influenced by a certain aggressive individual (O’Leary-Kelly et al., 1996).

Thus, bullying is seldom explained only by one factor alone, but is rather a multi-causal phenomenon (Zapf, 1999). What is more, bullying can often be described as a selfreinforcing or spiralling process, building on vicious circles (cf. Andersson \& Pearson, 1999). In addition, bullying and other forms of antisocial behaviour may also cascade and spawn secondary bullying spirals, either through modelling or displacement (cf. Pearson, Andersson \& Porath, 2000). Thus, during the bullying process many different factors may interact and be part of the explanation. By reviewing different kinds of explanations for workplace bullying we can better understand the logic behind the process. Hence, in this paper explanations of and factors associated with bullying behaviour are classified into three groups.

Firstly, necessary antecedents of bullying, i.e. enabling structures and processes, are discussed. Secondly, incentives for bullying colleagues or supervisors, i.e. motivating structures and processes, are presented. Finally, triggering circumstances, i.e. precipitating processes, are reviewed ${ }^{1}$. As shown in Figure 1 bullying can be

\footnotetext{
1 This framework is based on Boddewyn (1985) who has used it to classify theories on foreign investment and divestment into theories dealing with conditions, motivations, and precipitating circumstances.
} 
understood as the result of an interaction between these three groupings of explanators, or at least two of them. As argued by Boddewyn (1985): 'something [...] does not usually happen unless it is possible, beneficial and triggered'. Conditions in themselves may not usually lead to bullying, but act as enabling factors if there is an additional motivator or trigger present. Similarly, motivating and precipitating factors do not result in bullying, unless the conditions are right. In addition, attention should be drawn to the double significance of the enabling factors, which simultaneously act as a foundation and as a filter. The enabling factors can provide fertile soil for bullying, making the environment conducive to bullying. In addition, when there are motivating and/or precipitating structures or processes present, the existence or lack of enabling conditions in the organization will affect whether bullying is possible or not.

Hoel \& Cooper (2001) have pointed out that factors on many different levels may contribute to bullying and have discussed possible explanations in terms of individual dyadic, group, organizational, and societal factors. Since this paper is written mainly from a management perspective, the emphasis is on work environment factors, i.e. organizational factors and to some extent group level factors. Whereas management has little control over individual characteristics except in recruitment and promotion decisions, work environment factors are to a higher degree under the control of management, who may exert considerable influence for example on structure, reward systems and job design. Thus, although other factors beside organization level factors can be most relevant for understanding both why bullying occurs in the first place and why certain individuals are singled out, a thorough discussion of these factors is outside the scope of the paper. 


\section{Enabling structures and processes}

Enabling structures and processes include conditions that make it possible for bullying to occur in the first place, i.e. factors that provide fertile soil for bullying. These conditions include a perceived power imbalance between the possible victim and perpetrator(s), low perceived costs for the perpetrator, and dissatisfaction and frustration in the work environment.

\section{Perceived power imbalance}

Already when defining bullying it was argued that bullying is a very specific type of conflict, pushing the concerned individual into a helpless and defenceless position, thus involving a victim-perpetrator structure (e.g. Einarsen \& Skogstad, 1996; Leymann, 1996; Vartia, 1996). This indicates that a perceived power imbalance is a prerequisite for bullying to occur, since without it the person towards whom the aggression is directed could withstand the direct or indirect attacks and retaliate, thus preventing the bullying from beginning.

The importance of power structures and power imbalances in organizations can partly explain the large number of victims being bullied by supervisors. In many countries supervisors appear to make up a clear majority of all bullies or instigators of incivility (e.g. Cortina et al., 2001; Hoel \& Cooper, 2000; Knorz \& Zapf, 1996; O'Moore, 2000; Zapf et al., 1996). However, perceived power imbalances are not necessarily due to formal power differences, but can also be created by situational and contextual characteristics (cf. Cleveland \& Kerst, 1993). Thus, for example power differences associated with traditional gender roles and minority status may also affect bullying behaviour, as it can be assumed that women and minorities are perceived to have less 
power and status. In many countries women seem to report somewhat more victimisation than men (Aquino \& Bradfield, 2000; Cortina et al., 2001; Hoel \& Cooper; 2000; Zapf et al., 1996). What is more, employees in particularly exposed and visible situations, for example minorities, are more likely to become victims of bullying. This is supported by the finding that both members of 'non-white' ethnic groups (Hoel \& Cooper, 2000) and handicapped employees whose salaries are being subsidised by the state (Leymann, 1992b) show higher victimisation rates. Organizational power differences are thus often connected with societal power differences and bullying often overlaps with related phenomena such as sexism or racism in the workplace (cf. Hearn \& Parkin, 2001). This means that organizational policies and practices regarding discrimination of vulnerable groups and minorities are important in the creation or prevention of power imbalances in the organization.

The importance of power imbalances is further supported by the finding that bullying appears to be particularly prevalent in total institutions, such as the army and prisons, where dominance and power imbalances are strongly emphasized (cf. Ashforth, 1994; Ireland, 2000). Similarly, Archer (1999) found a high level of bullying in the U.K. Fire Service, which he described as a 'para-military' organization, characterised by rank structure, a highly authoritarian leadership style and a strong emphasis on conformity. In organizations where there are strong power imbalances there thus appears to exist a particular form of institutionalised bullying. Also in general a very autocratic style of management can be conducive to bullying (Hoel \& Cooper, 2000; O'Moore, 2000; Vartia, 1996). 


\section{Low perceived costs}

In addition to power imbalances, another prerequisite for bullying to occur is that the perpetrator assesses the costs of bullying as being relatively small. It can be argued that in some cases bullying can actually be described as an individually rational rent-seeking behaviour, based on a cost-benefit analysis (e.g. Kräkel, 1997). The costs then involve for example the risk of getting a reprimand, being dismissed, or being socially isolated and punished by colleagues.

The importance of perceived low costs and risks can be illustrated by the fact that bullying has been shown to be more frequent in large (Einarsen \& Skogstad, 1996; Leymann, 1992a) and bureaucratic organizations (Thylefors, 1987). Einarsen \& Skogstad (1996) have pointed out that the size and length and formality of decisionmaking processes in these companies make the individual less visible, thus reducing the risks for the perpetrator of being caught, punished or socially condemned.

In addition, there seems to be an association between bullying and leadership style. A laissez faire style of leadership or 'weak' or 'inadequate' leadership on higher levels in the organization seem to be conducive to bullying among colleagues (Einarsen et al., 1994; Hoel \& Cooper, 2000; Leymann, 1996). Thus, bullying seems to flourish when upper management abdicate responsibility and do not intervene in bullying. The relationship between bullying and weak leadership can be explained in terms of low perceived costs. Since it can be assumed that weak leaders seldom intervene in bullying situations, weak leadership further reduces the risk for the perpetrator being caught and condemned. 
What is more, organizational culture may also be used to explain workplace bullying. In some organizations bullying and other forms of harassment seem to be more or less 'permitted' as the way things are done. Already in 1976, Brodsky (1976: 83) stated that 'for harassment to occur, harassment elements must exist within a culture that permits and rewards harassment'. If there is no policy against bullying, no monitoring policy, and no punishments for those who engage in bullying, it might interpreted as if the organization accepts it, and a possible perpetrator will perceive the costs and dangers of bullying as very low. In some organizations, bullying may also be seen as an efficient means of accomplishing tasks. A quest for excellence - regardless of the costs - may also contribute to an acceptance of bullying. For example, the abusive behaviour of some top chefs can partly be attributed to such quests (cf. Johns \& Menzel, 1999). Similarly, some cultures may even celebrate the appearance of toughness (Neuman \& Baron, 1998).

What is more, modelling and imitation may influence the prevalence of bullying (cf. O’Leary-Kelly et al., 1996; Robinson \& O’Leary-Kelly, 1998). Bullying seems to flourish where new managers are socialised into a culture that treats bullying as a 'normal' and acceptable way of getting things done. Social learning theory suggests that individuals who operate in a work environment where others are rewarded for aggressive behaviour are more likely to engage in similar acts themselves (Bandura, 1973). Bullying can also be an initiation ritual or part thereof. The fact that many victims consider complaining about bullying to be an act of disloyalty further emphasizes the potential strength and impact of the socialisation process (Hoel \& Salin, 2003).

Further, Pearson et al. (2000) argue that with increasing informality and casual behaviour in organizations, it may be more difficult for some employees to distinguish 
what constitutes 'proper' and 'professional' interpersonal behaviour. Perceived hostility and injustice can also start escalating processes and a desire to reciprocate, thereby resulting in spirals of incivility or aggression (Andersson \& Pearson, 1999). Desensitizing processes may further lower the costs and dangers of bullying. The occurrence of violence and bullying may be a self-strengthening process in the sense that violence in the work community may become increasingly naturalised and takenfor-granted (Hearn \& Parkin, 2001).

In addition to 'permitting' bullying and 'tough' management, in some organizations the organizational culture may be characterised by a heavy reliance on jokes and banter, which may boarder upon bullying. For example, in tough male-dominated shop floor environments certain negative acts, such as humiliating jokes and 'funny surprises', can be part of the everyday life and an accepted part of the culture (Collinson, 1988; Einarsen \& Raknes, 1997). However, this kind of humour can easily go sour and turn into bullying, if the target for some reason cannot defend himself or take the jokes 'as a man'.

\section{Dissatisfaction and frustration}

In addition to a perceived power imbalance and low perceived costs, dissatisfaction and frustration with the working situation and the organizational climate have also been put forward by other researchers as conditions that may provide a good starting point for bullying and other forms of anti-social behaviour. This includes organizational constraints and a lack of control over one’s own job (Einarsen et al., 1994; Spector, 1997; Vartia, 1996; Zapf et al., 1996), lack of clear goals (Vartia, 1996) and role conflict and ambiguity (Einarsen et al., 1994; Spector, 1997). It has been hypothesised that factors in the physical work environment, such as crowding, uncomfortable temperatures and noise, may contribute to dissatisfaction and aggression at work 
(O’Leary-Kelly et al., 1996). Dissatisfaction and lack of clarity and control may lead to more irritation, lower tolerance, and a search for more stimulating activities, thereby providing the necessary conditions for bullying.

Furthermore, dissatisfaction with the social climate and the internal communication has been used to explain bullying. For example, Einarsen et al. (1994) and Vartia (1996) found a significant correlation between bullying and low satisfaction with the social climate. Moreover, deficient internal communication, i.e. poor information, lack of mutual conversations about tasks and goals, and a poor communication climate have been shown to correlate with bullying (Vartia, 1996).

Finally, a high degree of stress may also be conducive to dissatisfaction and bullying. Studies have shown that people with a high work-load, time pressure and a hectic work environment report more bullying (Appelberg, Romanov, Honlasalo \& Koskenvuo, 1991; Einarsen et al., 1994; Hoel \& Cooper, 2000). The effects of stress can thus partly be explained by the fact that stress increases job dissatisfaction and lowers aggression thresholds for the concerned individuals, and partly by the fact that it does not allow for time-consuming conflict solving. Thus, as argued by Pearson et al. (2000) intensified feelings of time pressure allow little time for the polite 'niceties' of business life, so increasing the risk for harsh and spiralling interpersonal conflicts.

\section{Motivating Structures and Processes}

In the former section structures and processes that provide good conditions for bullying were discussed. Although these, or at least some of these, may be necessary to explain bullying, they are seldom sufficient explanations. In addition to these conditions, there

are certain motivating circumstances that can actually make it rewarding to harass 
others in the workplace. Such motivational factors include high internal competition, certain forms of reward systems, and expected benefits for the perpetrator.

Some researchers have argued that bullying is not necessarily an irrational behaviour among frustrated workers, but that it can sometimes be explained as rent-seeking behaviour, i.e. behaviour that strives to enlarge the allocation and proportion of existing profits to a certain individual (e.g. Kräkel, 1997). Thus, if the necessary conditions are in place, for example, a perceived power imbalance and low perceived cost, and the perpetrator feels that he may actually benefit from bullying, he may engage in such behaviour.

There are several instances where it might be individually 'rational' or rewarding to bully a colleague or a subordinate. First of all, high internal competition and a politicised climate seem to make an organization particularly prone to bullying (O'Moore, 2000; Salin, 2003; Vartia, 1996). Secondly, the reward system may contribute to bullying. For example, if an organization promotes an employee who has succeeded by manipulating or harming a colleague, it is providing an incentive for others to do the same (O'Leary-Kelly et al., 1996). In addition, the reward system may give an employee an incentive to bully a colleague if the remuneration is based on relative ranking of the employees (Kräkel, 1997). By sabotaging the work performance of a colleague, the perpetrator may improve his own ranking. Similarly, work pressures and performance evaluations primarily based on quantity of production may have a negative effect on group cohesion, as this induces increased perceptions of internal competition (Klein, 1996). What is more, bullying can be used to discipline colleagues who are to perceived as violating established production norms and raising the barrier for others (Kräkel, 1997; Neuman \& Baron, 1998). Finally, if an employee is evaluated and remunerated based on the performance of the team he belongs to he may want to 
'punish' and expel very low performing team members. In this respect teamwork may at times lead to oppressive control from peers (Sewell \& Wilkinson, 1992). Similarly, the introduction of collective bonus systems may reinforce some workers' concern to discipline their colleagues (Collinson, 1988).

Employees may not only achieve higher pay, increased promotion opportunities, and improved performance appraisal as a result of engaging in bullying activities. For example, it has been argued that insults, which often play on hidden desires or vulnerabilities, can be a means both for establishing a pecking order and for allowing for a certain mobility within it (Gabriel, 1998). Similarly, among prison inmates bullying has also been reported to be a means of achieving status (Ireland, 2000). Similar processes can most probably also be found in some work environments.

What is more, the reward system and expected benefits may not only contribute to horisontal bullying, but may also contribute to vertical bullying, i.e. bullying from superiors. The reward system may encourage supervisors to try to get rid of very high or low performing subordinates (cf. Kräkel, 1997). First of all, a supervisor might perceive a very talented subordinate as a rival and a threat to his own career, and might therefore try to expel or sabotage the work performance of the subordinate. However, supervisorsubordinate bullying may also occur in the opposite case (Kräkel, 1997). When a superior knows that his own rating is based on the performance of his subordinates, a low performing subordinate might be perceived as a liability for the department. Thus, the superior may then hope that bullying or constant harassment will lead the subordinate to either request a transfer or leave the organization. The Banking, Insurance, and Finance Union (BIFU) in the UK has argued that 'the increased pressure on staff and managers to meet targets - especially unofficial targets - creates an environment in which intimidation and victimisation are almost unavoidable'. In line 
with this they take a very negative attitude towards performance-related pay and argue that such policies can 'virtually institutionalise' the practice of workplace bullying (Labour Research 1994, p. 16, in Lee, 2000).

Similarly, Zapf \& Warth (1997) have discussed that bullying may be 'personnel work by other means'. Thus, bullying can be used to expel a certain unwanted employee, whom it otherwise would be difficult to lay off. What is more, according to Lee (2000) MSF believes that bullying can be used as a way of getting rid of staff without making redundancy payments. As it is often more problematic within the public sector to lay off a certain employee due to more bureaucratic rules, this could also explain why several studies have reported somewhat higher bullying prevalence rates within the public than the private sector (O'Moore, 2000; Salin, 2001).

\section{Precipitating Processes}

In the two earlier sections structures and processes that can be classified as conditions or motivations were discussed. Although the enabling structures and processes explain why certain organizations and situations constitute more fertile soil for bullying and the motivating structures and processes explain why it can be rewarding to bully a colleague or subordinate, there are additional processes that often act as the actual triggers of bullying. Such precipitating processes are typically related to changes of the status quo and may include, for example, downsizing, other organizational changes and changes in the composition of the workgroup.

Research has shown that restructuring, downsizing and other crises are important changes that often precipitate bullying in organizations. Cost cutting, restructuring and reengineering seem to be significantly related to expressions of hostility and 
obstructionism (Baron \& Neuman, 1996; Hoel \& Cooper, 2000; McCarthy, 1996; Sheehan, 1996). Restructuring and downsizing lead to the elimination of layers and positions, thereby compressing promotion opportunities, increasing workloads and internal competition, and lowering job security. This in turn leads to higher pressures and more stress, lowering thresholds for aggression and increasing the potential benefits of 'eliminating' threats and burdens. What is more, downsizing and reengineering may result in general feelings of uncertainty and powerlessness. As argued by Ashforth (1989) and Bennett (1998) employees who feel powerless are more likely to engage in destructive or interpersonally deviant behaviour. Such deviant behaviours may have a retributive or corrective function, i.e. be motivated by an attempt to restore justice or a sense of control. Employees may thus try to elevate their own status by lessening other employees' prestige through belittling, rumours or other negative acts (cf. Bennett 1998).

Not only crises, but also other organizational changes can increase the prevalence of bullying. For example, a move towards new, flatter, decentralised structures reduces the number of managerial posts, thereby potentially increasing competition and enhancing the incentives to impede or eliminate competitors (Kräkel, 1997). Similarly, the delegation of control to semi-autonomous teams may affect co-worker relations negatively (cf. Hodson, 1997; Kräkel, 1997). The delegation of control also involves delegating sanction mechanisms to group members, without the power being institutionally regulated. This in combination with increased cooperation requirements and team-based compensation may further motivate employees to punish and expel low performing colleagues and other 'non-desirable' team members.

In addition, changes in management or in the composition of the work group have also been reported to increase the risk for bullying (Hoel \& Cooper, 2000; O’Moore, Seigne, 
McGuire \& Smith, 1998; Rayner, 1997). For example, in a study by O’Moore et al. (1998) almost two thirds of the victims stated that the bullying commenced after the promotion of the perpetrator or the arrival of a new manager. However, also other changes in the workgroup may precipitate bullying. For instance, increased workplace diversity in terms of age, gender and ethnicity has been associated with higher frequencies of workplace aggression (Baron \& Neuman, 1996). The differences may cause difficulty in interpersonal communication, or lead to mutual stereotyping, which in turn may trigger more aggressive behaviour.

\section{CONCLUSION}

In this paper structures and processes contributing to workplace bullying have been classified into three groupings: enabling, motivating, and precipitating structures and processes. The enabling structures were described as the necessary antecedents or the factors providing fertile soil for bullying. This category included a perceived power imbalance, low perceived costs, and dissatisfaction and frustration. The motivating structures described under what circumstances it might actually be rational for an individual to bully someone. This category included the reward system and expected benefits of eliminating threats or burdens. Finally, precipitating or triggering processes were discussed. These triggers included restructuring and downsizing, other organizational changes, and changes in the composition of the workgroup and management.

Bullying can thus be understood as the result of an interaction between these three groupings of explanators, or at least two of them. For bullying to occur enabling conditions must be in place and there must be additional motivating or triggering 
factors. There might also be further interaction effects between the three groupings, for example so that restructuring can lead to higher internal competition, thereby strengthening the motivation to bully and eliminate 'competitors'. The enabling factors can be thought of as a filter, which determine whether motivating or triggering factors can actually give rise to bullying in a certain work environment and situation. In terms of a particular dimension of perceived power imbalance, a weaker party cannot bully a stronger party although he might have strong incentives, and similarly possible perpetrators will most likely refrain from such behaviour despite expected benefits if they feel that the risks and costs of being caught and punished are too high. Nonetheless, this framework should not be seen as a final, complete model for explaining workplace bullying, but rather as a preliminary attempt to provide a richer picture of the mechanisms involved.

What is more, this framework builds on several different studies, which have been based on different ontological and epistemological assumptions, thus making some of the findings somewhat difficult to reconcile. The vast majority of the studies reviewed for this article have been conducted as survey studies measuring the respondents' exposure to pre-defined negative behaviours, e.g. by using scales such as the Negative Acts Questionnaire (Einarsen \& Raknes, 1997; Hoel \& Cooper, 2000; Salin, 2001), or the Workplace Incivility Scale (Cortina et al., 2001). In addition, some qualitative studies on bullying and hostile interpersonal behaviours have been carried out (e.g. Archer, 1999; Knorz \& Zapf, 1996; Lewis, 1998; O’Moore et al., 1998). Case studies on, for example, the effects of organizational restructuring (Sheehan, 1996) and masculinity and conflict on the shop floor (Collinson, 1988) have further contributed to our understanding of the dynamics of bullying. 
However, the present emphasis on surveys based on positivist assumptions limits our understanding of workplace bullying. First of all, using surveys makes it difficult to capture patterns and escalation processes, and surveys seldom provide enough data to identify the subjective meanings and experiences of the targets (cf. Keashly \& Jagatic, 2003; Lewis, 1998). In addition, the fact that most studies on bullying have relied on cross-sectional data and correlational designs makes it difficult to separate antecedents from consequences and to examine the importance of vicious circles (cf. Einarsen et al., 1994). As most of the surveys have been conducted among respondents who are presently employed, those who have been so severely traumatised by bullying that they have left work life are typically excluded from the studies. In addition, we have very limited information about the perpetrators of bullying and their perspective on bullying, as there are both practical and ethical considerations that make it difficult both to approach and study this group (cf. Rayner \& Cooper, 2003).

To further increase our understanding of the processes and factors leading to bullying, more qualitative, interpretivist and longitudinal studies should be encouraged. In addition, Bennett \& Robinson (2003) have suggested that for example event sampling methodology, critical incident method, and peer reports may provide additional useful, in-depth data for increasing our understanding of hostile interpersonal behaviours.

What is more, although a few researchers have depicted superior-subordinate bullying as a product of current HRM or other organizational practises (e.g. Lewis \& Rayner, 2003; Liefooghe \& Mackenzie Davey, 2001) or as a reflection of the nature of the employment relationship (e.g. Ironside \& Seifert, 2003), critical studies on workplace bullying still seem to be scarce and should be further encouraged. For example, such studies may provide alternative views on how bullying is not only a negative and dysfunctional behaviour from the point of view of the organization, but may actually be 
used to elicit wanted behaviour from employees and increase productivity within systems of domination. Such a perspective may also provide further insights on the relationship between power and bullying, and the societal context and the societal relations within which bullying is defined and recognised (cf. Hearn \& Parkin, 2001).

What is more, it should be kept in mind that bullying can be related to different aspects of the work environment in different kinds of organizations (Einarsen et al., 1994). For example, Einarsen et al. (1994) reported a stronger relation between dissatisfaction with leadership and bullying for administrative workers interacting with their superiors on a daily basis than for teachers who work rather independently. Thus, different work environment characteristics are of different importance for bullying in different professions.

Regardless of sector and function studied it should always be remembered that bullying is a complex process, where a number of different structures and processes interact. In addition to the three groups of enabling, motivating and precipitating structures and processes in the work environment, factors on other levels should also be taken into consideration in a complete analysis of the causes of bullying. A more complete model should thus also incorporate processes and factors on the individual, dyadic, and societal levels. For instance, certain target or perpetrator characteristics may lead to or reinforce perceived power imbalances, thereby enabling bullying. For example, positive correlations between victimization on one hand and negative affectivity, low selfdetermination, and aggressiveness on the other have been reported (Aquino et al., 1999; Aquino \& Bradfield, 2000). Similarly, some victim characteristics such as dependence, instability, introversion and conscientiousness can further affect perceptions of power differences and lessen the risks of the target being able to retaliate efficiently (Coyne et al., 2000). 
Furthermore, an increasing number of researchers are pointing to larger societal forces, such as globalization and liberalising markets, an ever-increasing struggle for efficiency, and performance-related reward systems, that may lead to an increase in bullying (Lee, 2000; McCarthy, 1996; Sheehan, 1996). McCarthy (1996: p. 48) further argues that 'pressures generated by these forces lower the threshold at which managers, particularly those operating at the limits of their skills competencies, might adopt bullying behaviours - even if involuntarily'. Such forces may thus affect all three groupings of explanations. Firstly, they may facilitate bullying by reducing the costs and risks associated with bullying, as bullying is turned into 'acceptable' and 'normal' behaviour. Secondly, these forces may increase the 'value' of bullying as a way of eliminated 'burdens' and 'threats' when internal competition increases. Thirdly, they may increase stress and lower the threshold for aggression, thereby triggering bullying.

To gain a broader understanding of bullying also factors outside the organization must be taken into consideration. An examination of societal forces and changes that enable, motivate and trigger bullying is thus an important venue for further research in the area.

\section{ACKNOWLEDGEMENTS}

The author would like to thank Jeff Hearn and Anne Kovalainen for helpful comments on earlier drafts of this paper. In addition, thanks are due to three anonymous reviewers for their helpful comments and suggestions.

\section{REFERENCES}

ANDERSSON, L. M., \& PEARSON, C. M. Tit for tat? The spiraling effect of incivility in the workplace. Academy of Management Review, 1999, 24, 452-471.

APPELBERG, K., ROMANOV, K., HONLASALO, M., \& KOSKENVUO, M. Interpersonal conflicts at work and psychosocial characteristics of employees. Social Science Medicine, 1991, 32, 1051-1056. 
AQUINO, K., \& BRADFIELD, M. Perceived victimization in the workplace: the role of situational factors and victim characteristics. Organization Science, 2000, 11 (5), 525-537.

AQUINO, K., GROVER, S., BRADFIELD, M., \& ALLEN, D. The effects of negative affectivity, hierarchical status, and self-determination on workplace victimization. Academy of Management Journal, 1999, 42 (3), 260-272.

ARCHER, D. Exploring "bullying" culture in the para-military organisation. International Journal of Manpower, 1999, 20 (1/2), 94-105.

ASHFORTH, B. E. The experience of powerlessness in organizations. Organizational Behavior and Human Decision Processes, 1989, 43, 207-242.

ASHFORTH, B. E. Petty tyranny in organizations. Human Relations, 1994, 47 (7), 755778.

BARON, R. A., \& NEUMAN, J. H. Workplace violence and workplace aggression: evidence on their relative frequency and potential causes. Aggressive Behavior, 1996, 22, 161-173.

BANDURA, A. Aggression: a social learning analysis. Englewood Cliffs. NJ: Prentice Hall, 1973.

BENNETT, R. J. Perceived powerlessness as a cause of employee deviance. In Griffin, R., O’Leary-Kelly, A.M., \& Collins, J. (Eds) Dysfunctional behavior in organisations. Stanford, CT: JAI Press, 1998.

BENNETT, R. J., \& ROBINSON, S. L. The past, present and future of workplace deviance research. In Greenberg, J. (Ed.) Organizational behavior: the state of the science, $2^{\text {nd }}$ edition. Mahwah, NJ: Lawrence Erlbaum, 2003.

BODDEWYN, J. Theories of foreign direct investment and divestment: a classificatory note. Management International Review, 1985, 25 (1), 57-65.

BRODSKY, C. M. The Harassed Worker. Toronto: Lexington Books. DC Heath and Company, 1976.

CLEVELAND, J. N., \& KERST, M. E. Sexual harassment and perceptions of power: an under-articulated relationship. Journal of Vocational Behavior, 1993, 42 (1), 49-67.

COLLINSON, D. L. 'Engineering humour': masculinity, joking and conflict in shopfloor relations. Organization Studies, 1988, 9 (2), 181-199.

CORTINA, L. M., MAGLEY, V. J., WILliAMS, J. H., \& LANGHOUT, R. D. Incivility in the workplace: incidence and impact. Journal of Occupational Health Psychology, 2001, 6 (1), 64-80.

COYNE, I., SEIGNE, S., \& RANDALL, P. Predicting workplace victim status from personality. European Journal of Work and Organizational Psychology, 2000, 9 (3), 335-349. 
DUFFY, M. K., GANSTER, D. C., \& PAGON, M. Social undermining in the workplace. Academy of Management Journal, 2002, 45 (2), 331-351.

EINARSEN, S. Bullying and harassment at work: epidemiological and psychosocial aspects. Doctoral dissertation. Department of Psychosocial Science. Faculty of Psychology. University of Bergen, 1996.

EINARSEN, S., \& RAKNES, B. I. Harassment in the workplace and the victimization of men. Violence and Victims, 1997, 12, 247-263.

EINARSEN, S., \& SKOGSTAD, A. Bullying at work: epidemiological findings in public and private organizations. European Journal of Work and Organizational Psychology, 1996, 5 (2), 185-201.

EINARSEN, S., RAKNES, B. I., \& MATTHIESEN, S. B. Bullying and harassment at work and their relationships to work environment quality: an exploratory study. European Work and Organizational Psychologist, 1994, 4 (4), 381-401.

GABRIEL, Y. An introduction to the social psychology of insults in organizations. Human Relations, 1998, 51 (11), 1329-1354.

GIACALONE, R.A., \& GREENBERG, J. Antisocial behavior in organizations. Thousand Oaks: Sage Publications, 1997.

HEARN, J., \& PARKIN, W. Gender, sexuality and violence in organizations. London: Sage Publications, 2001.

HODSON, R. Group relations at work: solidarity, conflict, and relations with management. Work \& Occupations, 1997, 24 (4), 426-452.

HOEL, H., \& COOPER, C. L. Destructive Conflict and Bullying at Work, Manchester School of Management, University of Manchester Institute of Science and Technology, 2000.

HOEL, H., \& COOPER, C. L. Origins of bullying: theoretical frameworks for explaining workplace bullying. In N. Tehrani: Building a Culture of Respect: Managing Bullying at Work. London: Taylor \& Francis, 2001

HOEL, H., \& SALIN, D. Organisational antecedents of workplace bullying. In Einarsen, S., Hoel, H., Zapf, D., \& Cooper, C. (Eds) Bullying and emotional abuse in the workplace: International perspectives in research and practice. London: Taylor \& Francis, 2003.

HOEL, H., EINARSEN, S., \& COOPER, C. Organisational effects of bullying. In Einarsen, S., Hoel, H., Zapf, D., \& Cooper, C. (Eds) Bullying and emotional abuse in the workplace: International perspectives in research and practice. London: Taylor \& Francis, 2003.

IRELAND, J. L. "Bullying" among prisoners: a review of research. Aggression and Violent Behavior, 2000, 5 (2), 201-215. 
JEHN, K. A multimethod examination of the benefits \& detriments of intragroup conflict. Administrative Science Quarterly, 1995, 40(2), 256-282.

IRONSIDE, M., \& SEIFERT, R. Tackling bullying in the workplace: the collective dimension. In Einarsen, S., Hoel, H., Zapf, D., \& Cooper, C. (Eds) Bullying and emotional abuse in the workplace: International perspectives in research and practice. London: Taylor \& Francis, 2003.

JOHNS, N., \& MENZEL, P. J., 'If you can't stand the heat!'...kitchen violence and culinary art. Hospitality Management, 1999, 18, 99-109.

KEASHLY, L. Emotional abuse in the workplace: conceptual and empirical issues. Journal of Emotional Abuse, 1998, 1 (1), 85-117.

KEASHLY, L., \& JAGATIC, K. By any other name: American perspectices on workplace bullying. In Einarsen, S., Hoel, H., Zapf, D., \& Cooper, C. (Eds) Bullying and emotional abuse in the workplace: International perspectives in research and practice. London: Taylor \& Francis, 2003.

KLEIN, S. A longitudinal study of the impact of work pressures on group cohesive behaviors. International Journal of Management, 1996, 13 (1), 68-75.

KNORZ, C., \& ZAPF, D. Mobbing - eine extreme Form sozialer Stressoren am Arbeitsplatz. Zeitschrift für Arbeits- und Organisationspsychologie, 1996, 40 (1), 12-21.

KRÄKEL, M. Rent-seeking in Organisationen - eine ökonomische Analyse sozial schädlichen Verhaltens. Schmalenbachs Zeitschrift für Betriebswirtschaftliche Forschung, 1997, 49 (6), 535-555.

LEE, D. An analysis of workplace bullying in the UK. Personnel Review, 2000, 29 (5), 593-612.

LEWIS, D. Workplace bullying. In Richardson, J., \& Shaw, A. (Eds) The body in qualitative research. Aldershot: Ashgate Publishing Ltd, 1998.

LEWIS, D., \& RAYNER, C. Bullying and human resource management: a wolf in sheep’s clothing? In Einarsen, S., Hoel, H., Zapf, D., \& Cooper, C. (Eds) Bullying and emotional abuse in the workplace: International perspectives in research and practice. London: Taylor \& Francis, 2003.

LEYMANN, H. Vuxenmobbning på svenska arbetsplatser. En rikstäckande undersökning med 2.428 intervjuer. Stockholm: Arbetarskyddsstyrelsen, 1992a.

LEYMANN, H. Lönebidrag och mobbad. En svag grupps psykosociala arbetsvillkor i Sverige. Stockholm: Arbetarskyddsstyrelsen, 1992b.

LEYMANN, H. The content and development of mobbing at work. European Journal of Work and Organizational Psychology, 1996, 5 (2), 165-184.

LIEFOOGHE, A., \& MACKENZIE DAVEY, K. Accounts of workplace bullying: the role of the organization. European Journal of Work and Organizational Psychology, 2001, 10 (4), 375-392. 
MCCARTHY, P. When the mask slips: inappropriate coercion in organisations undergoing restructuring. In McCarthy, P., Sheehan, M., \& Wilkie, D. (Eds) Bullying: from backyard to boardroom. Alexandria: Millennium Books, 1996.

NEUMAN, J. H., \& BARON, R. A. Workplace violence and workplace aggression: evidence concerning specific forms, potential causes, and preferred targets. Journal of Management, 1998, 24 (3), 391-419.

O'LEARY-KELLY, A. M., GRIFFIN, R. W. \& GLEW, D. J. Organization-motivated aggression: a research framework. Academy of Management Review, 1996, 21 (1), 225253.

O'MOORE, M. Summary report on the national survey on workplace bullying in Ireland. Dublin: The Anti-Bullying Research Centre, Trinity College, 2000.

O’MOORE, M., SEIGNE, E., MCGUIRE, L., \& SMITH, M. Victims of bullying at work in Ireland. Journal of Occupational Health and Safety: Australia and New Zealand, 1998, 14 (6), 568-574.

PEARSON, C.M., ANDERSSON, L.M., \& PORATH, C.L. Assessing and attacking workplace incivility. Organizational Dynamics, 2000, 29 (2), 123-137.

PRYOR, J. B., \& FITZGERALD, L. F. Sexual harassment research in the United States. In Einarsen, S., Hoel, H., Zapf, D., \& Cooper, C. (Eds) Bullying and emotional abuse in the workplace: International perspectives in research and practice. London: Taylor \& Francis, 2003.

RAYNER, C. The incidence of workplace bullying. Journal of Community and Applied Social Psychology, 1997, 7 (3), 199-208.

RAYNER, C., \& COOPER, C.L. The black hole in 'bullying at work' research. International Journal of Management and Decision-Making, 2003, 4 (1), 47-64.

ROBINSON, S. L., \& BENNETT, R. J. A typology of deviant workplace behaviors: a multidimensional scaling study. Academy of Management Journal, 1995, 38 (2), 555572.

ROBINSON, S. L., \& O'LEARY-KELLY, A. M. Monkey see, monkey do: the influence of work groups on the antisocial behavior of employees. Academy of Management Journal, 1998, 41 (6), 658-672.

SALIN, D. Prevalence and forms of bullying among business professionals: a comparison of two different strategies for measuring bullying. European Journal of Work and Organizational Psychology, 2001, 10 (4), 425-441.

SALIN, D. Bullying and organisational politics in competitive and rapidly changing work environments. International Journal of Management and Decision Making, 2003, 4 (1), 35-46.

SEWELL, G., \& WILKINSON, B. Empowerment or emasculation? In Blyton and Turnbull (Eds) Reassessing human resource management. London: Sage, 1992. 
SHEEHAN, M. Case studies in organisational restructuring. In McCarthy, P.; Sheehan, M. \& Wilkie, D. (Eds) Bullying: from backyard to boardroom. Alexandria: Millennium Books, 1996.

SPECTOR, P. E. The role of frustration in anti-social behavior at work. In Giacalone, R.A., \& Greenberg, J. (Eds) Antisocial behavior in organizations. Thousand Oaks: Sage Publications, 1997.

THYLEFORS, I. Syndabockar - om utstötning och mobbning i arbetslivet. Natur och Kultur. Stockholm, 1987.

VARTIA, M. The sources of bullying - psychological work environment and organizational climate. European Journal of Work and Organizational Psychology, 1996, 5 (2), 203-214.

VARTIA, M. Consequences of workplace bullying with respect to the well-being of its targets and the observers of bullying. Scandinavian Journal of Work Environment Health, 2001, 27 (1), 63-69.

ZAPF, D. Organisational, work group related and personal causes of mobbing/bullying at work. International Journal of Manpower, 1999, 20 (1/2), 70-85.

ZAPF, D., \& WARTH, K. Mobbing: Subtile Kriegsführung am Arbeitsplatz. Psychologie Heute, August 1997, 20-25; 28-29.

ZAPF, D., KNORZ, C., \& KULLA, M. On the relationship between mobbing factors, and job content, social work environment, and health outcomes. European Journal of Work and Organizational Psychology, 1996, 5 (2), 215-237. 
FIGURE 1 - WORK ENVIRONMENT FACTORS CONTRIBUTING TO BULLYING

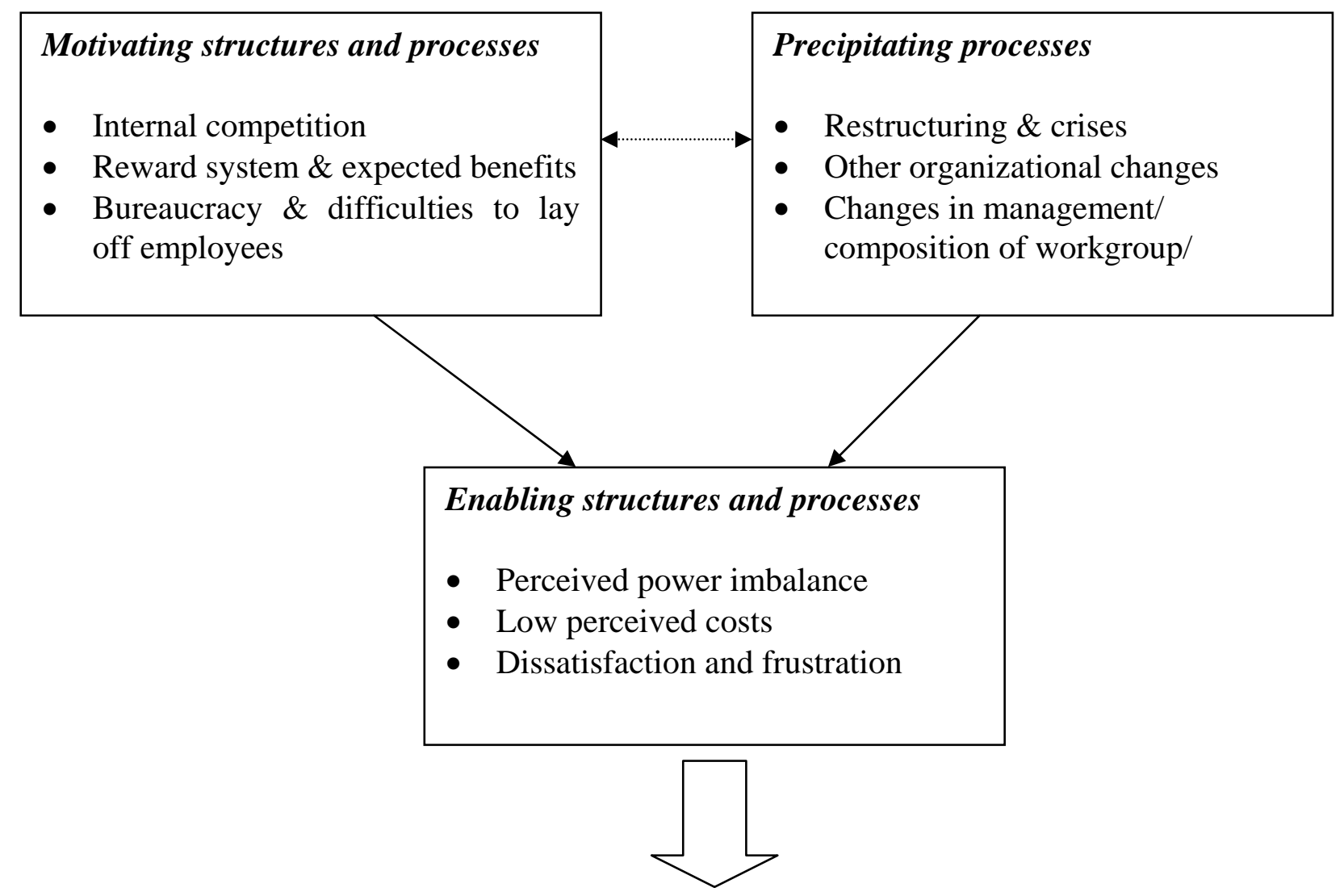

BULLYING POSSIBLE AND MORE

LIKELY

Figure 1. Enabling, motivating and precipitating structures and processes in the work environment. 